
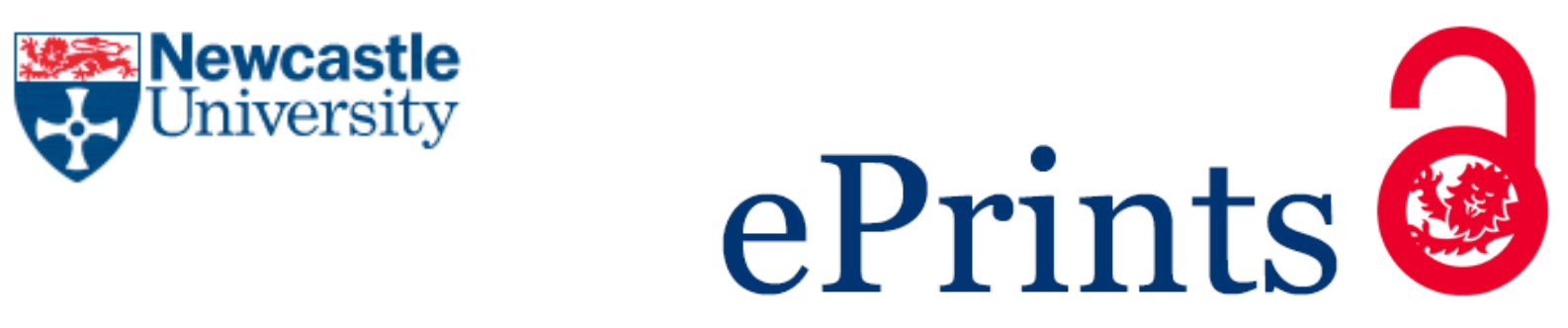

Sweet MJ, Bythell JC.

The role of viruses in coral health and disease.

Journal of Invertebrate Pathology 2017, 147, 136-144.

\title{
Copyright:
}

(C) 2017. This manuscript version is made available under the CC-BY-NC-ND 4.0 license

DOI link to article:

https://doi.org/10.1016/i.jip.2016.12.005

Date deposited:

$18 / 09 / 2017$

Embargo release date:

18 December 2017

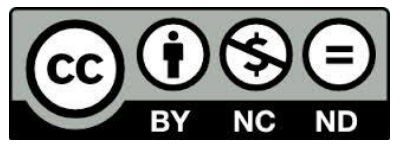

This work is licensed under a

Creative Commons Attribution-NonCommercial-NoDerivatives 4.0 International licence 


\section{The role of viruses in coral health and disease}

$2 \quad$ Michael Sweet ${ }^{1 *}$ John Bythell ${ }^{2}$

$3{ }^{1}$ Molecular Health and Disease Laboratory, Environmental Sustainability Research Centre,

4 College of Life and Natural Sciences, University of Derby, Derby, UK, DE22 1GB

$5 \quad{ }^{2}$ School of Biology, Newcastle University, Newcastle upon Tyne, UK, NE1 7RU

6

7

8

$9 \quad *$ corresponding author; m.sweet@derby.ac.uk

10

11

12

13

14

15

16

17

18

19

20

21

22 
Metagenomic and electron microscopy studies confirm that the coral microbiome contains a rich diversity and abundance of viruses. While there have been no definitive tests of disease causation by viruses in corals, viruses have been implicated as coral pathogens in a number of studies. Growing evidence also indicates that latent viral infections can compromise the algal symbionts under environmental stress and may be involved in the coral bleaching response. Conversely, bacteriophages and archaeal phage viruses are abundant in the microbiome of healthy corals and are likely to be involved in complex ecological networks, genetic material transfer and selective co-evolution within the surface mucus layers and tissues. The relative importance of viral control of bacterial and archaeal populations is unknown, but they are almost certain to be exerting some level of control on the composition and maintenance of the coral microbiome. While rapid leaps in the capability to detect viruses have been made due to advances in metagenomics and bioinformatics, these approaches need now to be integrated with in vitro culture and challenge experiments to assess the functional roles of viruses in health and disease, and it is imperative that interactions with other members of the coral microbiome are taken into account when assessing disease causation.

\section{Introduction}

It is only relatively recently that the ecological importance of viruses in marine systems has become evident (Suttle, 2007). For example viruses have been shown to be major contributors to mortality and the structuring of plankton communities (Gustavsen et al., 2014). Indeed, virioplankton densities in the oceans are estimated to be on the order of $10^{6}$ to $10^{8} \mathrm{ml}^{-1}$, which is roughly 5 to 25 times higher than that of bacterial population densities (Bergh et al., 1989; Fuhrman, 1999) and new groups of marine viruses continue to be discovered (Labonté and Suttle, 2013; Thurber and Correa, 2011). Along with influencing planktonic communities, viruses also play important roles as both pathogens and symbionts of metazoans, often with complex environmental controls on the degree of mutualism between the host and the virus (Roossinck, 2015, 2011; Suttle, 2007). Although our ability to describe these communities has developed rapidly with the advent of next generation sequencing, their ecological roles in health and disease are typically poorly understood. In reef building corals for example a significant diversity of viruses have now been described in 
healthy and diseased states (see Wood-Charlson et al., 2015 for a list of those currently described), but their roles are only beginning to be elucidated. Determining causation of coral diseases in general has proven to be a highly contentious and difficult area (Lesser et al., 2007) and history has shown that determining causation of viral diseases is likely to be even more challenging (Halstead and Cohen, 2015). Complications associated with the evaluation of cause and effect in pathogenesis arise as viral infections are known to trigger and in some cases control the host's cell death mechanisms and inflammatory responses, amongst other cellular process (Teodoro and Branton, 1997). Furthermore, several viruses have now been implicated in carrying and controlling virulence factors of bacterial pathogens, including the coral pathogen Vibrio coralliityicus, which demonstrates the potentially complex etiology of transmissible diseases in these basal metazoans (Cohen et al., 2013).

The first characterization of viruses associated with corals was in a study by Wilson et al., (2005). In this study, virus-like particles (VLPs) were detected in both healthy and heatstressed colonies of the coral Pavona danai. VLPs of 30-40 nm and 50-60 nm in diameter were described in healthy tissues, whilst in the heat-shocked coral, VLPs were 40-50 nm and 60-80 $\mathrm{nm}$. These findings led the authors to suggest that an outbreak of latent pathogenic virus had occurred. One year later, another study, using similar methodology showed a similar pattern with variation in size and abundance of VLPs in heat-stressed Acropora formosa (Davy et al., 2006). Since these early studies, a wide variety of viral types have been described in association with the symbiotic algae, the coral tissue and the surface mucus layer of reef corals (Wood-Charlson et al., 2015).

In other systems, numerous triggers have been associated with viral propagation and infection. These include for example: elevated temperatures (Danovaro et al., 2011), UV radiation (Jacquet and Bratbak, 2003), pH (Baumann et al., 2016) and the availability of nutrients (Scanlan and Wilson, 1999). All these environmental stressors have also been implicated in coral disease and bleaching outbreaks (Douglas, 2003; Bruno et al., 2007; Israely et al., 2001; Lesser and Farrell, 2004). A correlation between abundance and diversity of viruses and bleaching and environmental stress, is therefore not unexpected. As with any potential pathogen, distinguishing primary pathogens from opportunistic pathogens and secondary invaders is difficult, but the added dimension of viral latency and the potential disconnect between the temporal sequence of infection and disease adds further complexity 
to the determination of causality. The release of latent viruses due to environmental stress, as proposed in the earliest studies of coral-associated viruses (Davy et al., 2006; Wilson et al., 2005) and specifically demonstrated in the association of viruses and the symbiotic algae of corals following environmental stress ( Lohr et al., 2007; Lawrence et al., 2015), demonstrates that assessing causality in relation to viral pathogens is a significant challenge.

In this review we will address the current knowledge of the diversity of viruses associated with healthy and diseased corals, assessing where in the holobiont they have been found, what types have been identified and addressing their potential roles. We will also examine the methods that have been utilised to characterise the viral communities and explore other potential roles specific viral types may play in the health and disease of corals by drawing on studies from other organisms. We also propose a modern interpretation of Koch's postulates suitable for the metagenomics era and a whole-microbiome approach.

\section{The role of viruses in coral health}

Viral abundance has been shown to vary across both small and large spatial scales in reef systems, for example between depths and between lagoon waters and the reef crest (Seymour et al., 2005). Abundance of viruses appears to increase with proximity to coral colonies, with the highest abundances recorded 0-4 cm above the tissue surface (Seymour et al., 2005; Thurber and Correa, 2011). On the coral itself, even higher abundances of viruses occur within the surface mucus layer (SML) of the corals, with a threefold higher density being observed compared to the overlying water column (Leruste et al., 2012; Nguyen-Kim et al., 2014). In the SML, a diverse range of viruses have been described, encompassing bacterial, archaeal and eukaryotic viruses (Davy and Patten 2007; Marhaver et al. 2008; Vega Thurber et al. 2008; Wood-Charlson et al. 2015). The SML is also well known to host abundant and diverse communities of bacteria (Kemp et al., 2015), and the role of viruses in the control of potentially pathogenic bacteria is a rapidly emerging area (Glasl et al., 2016). The control of bacterial populations is governed by two major biotic processes in the majority of systems studied: predation (mainly by heterotrophic nanoflagellates and ciliates; (Sanders and Wickham, 1993)) and viral lysis (Fuhrman, 1999). The abundance and diversity of phages strongly suggests that viral lysis also plays a significant important role in controlling bacterial populations within the coral microbiome (Wood-Charlson et al., 2015). Interaction network 
analysis (based on metatransciptomic data) could be a useful tool to assess such patterns and directly explore the roles phages play in governing other members of the coral microbiome (Daniels et al., 2015).

117 A well-described example of phage-mediated control in corals is BA3-phage (Atad et al., 2012), which is able to infect Thalassomonas loyana, a bacterium proposed as the causal agent of some forms of white plague disease (Efrony et al., 2009; Soffer et al., 2015; Daniels et al., 2015). Natural variations in such associated viruses may explain why some coral colonies appear more resistant to certain diseases than others. Barr et al. (2013) took this idea further and proposed that viruses associated with the mucus may constitute a 'lytic barrier' against bacterial pathogen colonization, suggesting that viruses should be classed as an active part of the corals' innate immune system (Fig 1) (Bettarel et al., 2015; Soffer et al., 2015). Enrichment of phages in other mucus-rich environments has been shown to occur via interactions between mucin glycoproteins and Ig-like protein domains on phage capsids. Specifically, the phage Ig-like domains bind various glycan residues that coat the mucin glycoprotein component of the mucus (Barr et al., 2013). From these observations, a specific model was hypothesised and named the bacteriophage-adhering-to-mucus (BAM) model. The authors suggest that the surface mucus layer and phages may have coevolved, with phage adherence maintained as it benefits the corals by limiting potentially pathogenic bacteria in the mucus layer, and benefits the phage by enabling more frequent interactions with bacterial hosts.

The BAM model also incorporates a mechanism to support the specific association of mutualistic bacteria with the host. During stable environmental conditions, the mucuslysogenic infection could provide protection to bacterial symbionts by conferring associated phages may maintain lysogenic infections of the bacterial associates, with the bacteria remaining able to fulfil their normal ecological functions (Barr et al., 2013). Such immunization against lytic viruses (Barr et al., 2013). Such a strategy may mean that the phages ensure their proliferation on the coral surface, in a mechanism similar to that seen generally in marine biofilms (Abedon, 2011). Transient, non-symbiotic bacteria entering the SML from the surrounding water column which were not targeted by protective lysogenic phage infection would be exposed to infection by lytic phages (Barr et al., 2013), contributing to the control of their population densities. Nguyen-Kim et al., (2014) showed that the SML 
showed lytic viral production rates 9.5 times that of the surrounding seawater, supporting viral lysis as a strong controlling factor on the associated bacterial populations. Under adverse environmental conditions, the normally benign lysogenic infection of mutualistic bacteria may revert to lysis, impacting mutualistic bacterial populations which normally contribute to the invasion resistance of the host. Additionally, the normally lytic virulent phages may be inactivated by stress (Maranger et al., 2002; Noble and Fuhrman, 1997) and thus no longer able to control the proliferation of non-mutualistic bacterial populations. Either or both of these mechanisms could contribute to the dramatic stress-mediated increases in nonmutualistic bacterial associates observed by Ritchie, (2006) and others. The BAM model and the viral 'Iytic barrier' of the SML therefore provides an evolutionary framework for a complex process of selective co-evolution of a phage-bacterial-host associated microbiome. WoodCharlson et al. (2015) noted that viral metagenomic data often shows contamination from cellular gene sequences, but the potential for horizontal gene transfer between the members of the microbiome is another mechanism that might allow rapid evolution between partners, and the extent to which such sequences represent contamination or mobile DNA elements requires further investigation.

Several lines of evidence therefore support a role of viruses in the control of coral-associated bacterial communities, including the well-described role of viruses in the ecology of marine plankton communities, the dominance of bacteriophage sequences in the coral virome, increased viral lysis rates in the SML and the complex associations proposed in the BAM model. It therefore appears likely that viruses could be associated with control of potentially pathogenic bacterial associates and promotion of symbiotic associations. Cultureindependent metagenetics studies of coral-associated bacteria routinely detect the reported primary bacterial pathogens of coral diseases in non-diseased corals and other reef substrates and microhabitats (reviewed by Sweet et al. 2011), and a diversity of potential pathogens, typically dominated by vibrios, have been shown to proliferate under environmental stress in culture-based studies (Ritchie, 2006), implying that they are widespread in the reef environment. In turn, this suggests that it may be the control of populations of these nonspecific potential pathogens, rather than exposure of the host to a specific virulent pathogen that determines disease causation (Lesser et al., 2007). Thus, viruses may be indirectly 
involved in controlling potentially pathogenic bacterial populations and disease prevalence (Fig 1).

\section{Do viruses act as primary pathogens of coral disease?}

Viral metagenomics studies reveal a high diversity of eukaryotic viruses in addition to the dominance of bacteriophage-associated sequences (Wood-Charlson et al., 2015). Of the $>20$ described coral diseases globally, only 8 have specific pathogens ascribed to their aetiology (reviewed by Sheridan et al., 2013), suggesting that either the majority of these diseases are caused by complex aetiology that is not readily amenable to challenge experiments and/or the primary causal agents have not yet been cultivated. Viruses represent an obvious group of candidate pathogens which have been understudied with regard to their role as agents of coral disease. Viral agents may act in a number of ways, including primary infection, reactivation of latent infection, immune suppression (i.e. a reduction of the activation or efficacy of the immune system), and/or immune senescence (i.e. the gradual deterioration of the immune system brought on by natural ageing).

To date, a wide diversity of viruses have been shown by metagenomic analyses to be associated with corals and their associated microbiome, belonging to at least 50 of the 87 currently-recognised viral families (see King et al., 2012; Wood-Charlson et al., 2015). These include mainly double-stranded DNA (dsDNA) viruses, including bacteriophages and archaeal phages, single-stranded DNA (ssDNA) and both dsRNA and ssRNA viruses, including retroviruses. Some of these are likely to be environmental contaminants with no role in coral ecology or viruses infecting other associated eukaryotes such as protists and other plankton, including prey items consumed by the host coral. However, at least some of these viruses are likely to be coral host-specific or specific to the symbiotic algae and may act as primary pathogens in coral disease. In addition to these known groups, a number of viral sequences have been detected that could not be assigned to any known families of viruses, indicating that the coral microbiome is a rich environment for novel viral discoveries. However, only a few studies have focused on describing viral communities associated with specific coral diseases. In particular, only four diseases have been correlated with VLP presence that is absent or rare in the healthy coral: 
Corals showing signs of white syndrome (WS) appear to harbour increased VLP densities ( 30\%) in their tissues when compared to healthy corals of the same species collected in the same location (Patten et al., 2008). Interestingly, this increase in abundance appears to be dominated by relatively few VLP morphologies. In healthy tissues of Acropora muricata for example, a diverse array of different sized VLPs were described, whilst the same corals showing signs of WS were dominated by only two main types (Patten et al., 2008). These included a VLP of icosahedral morphology with a capsid diameter of 120-150 nm and no tail or envelope and another of a similar morphology but slightly larger (160-190 nm). Patten et al. (2008) hypothesised that the corals had become infected with these viruses and identified them as members of the Phycodnaviridae and/or Iridoviridae families. Caution must be used in identifying viruses by morphology alone, since our knowledge of morphotype diversity is continually being reviised. Furthermore, in other systems, some VLPs have been characterised as multiprotein structures that mimic the organization and conformation of viruses yet lack viral genomes (Roldão et al., 2010). However, viroplasms were also observed associated with coral colonies displaying signs of WS and both of these viral families have been shown to form these inclusion bodies (Fauquet et al., 2005; Novoa et al., 2005; Vega Thurber and Correa 2011).

Pollock et al. (2014) also highlighted an increase in VLP abundance (by 65\%) in colonies of Acropora hyacinthus showing signs of WS. In this study, the majority (87\%) of these fell in the sub-100 nm size range, compared to only $7 \%$ which were found in this range in healthy tissues. While the authors rightly noted that such shifts do not necessarily indicate disease causation, they suggested that they may provide diagnostic criteria to discriminate between distinct, but macroscopically similar WS and WS-like coral diseases (Pollock et al., 2014).

White plague

Barash et al., (2005) were the first to observe small $(0.2 \mu \mathrm{m})$ filterable factors within white plague-like infections of Red Sea Favia and Goniastrea corals. However, at the time it was not confirmed whether these were viruses. Although a bacterial pathogen (Thalassomonas loyana) has also been described for this WP-like disease, a recent study by (Soffer et al., 2014) suggested a viral pathogen could be a possible alternative candidate. In this latter study, single-stranded DNA viruses (ssDNA) were observed to dominate samples of tissue showing 
signs of WP, whereas they were undetectable in healthy tissues. Another VLP similar in morphology and sequence to a Nanoviridae was also reported in higher abundance in WP tissues than in either bleached and/or healthy tissues. Interestingly in bleached corals present at the same location, large DNA viruses (including one similar to a poxvirus) and a herpes-like virus (Herpesviridae), were also recorded together with a reduction in the abundance of the same ssDNAs observed in WP samples (Soffer et al., 2014).

\section{Porites white patch syndrome}

Séré et al., (2015) fulfilled Koch's postulates for this disease with the bacterial pathogen Vibrio tubiashii, however the experiments did not take into account potential viral pathogens. Indeed, another study, conducted at a different location highlighted two VLPs that appeared to increase in abundance in Porites white patch syndrome (PWPS) compared to healthy samples (Lawrence et al., 2015). Specifically, these included a small ( $<50 \mathrm{~nm}$ diameter) icosahedral VLP associated with the host tissue and an apparent, but not statistically significant, increase in abundance of filamentous viruses in the symbiotic algae (Lawrence et al., 2015). The authors of this latter study also highlighted that there were no significant differences in the prokaryote and eukaryote communities between healthy and diseased tissues, a result in direct contrast to Séré et al., (2015) and this led them to propose that one or both of these viruses were primary causal agents of PWPS.

\section{Caribbean yellow band disease / Yellow blotch disease}

Although the majority of research associated with this disease (now commonly referred to as Caribbean Yellow Band Disease) has focused on bacterial communities (Cervino et al., 2008; Cróquer et al., 2013) an earlier paper reported VLPs of 100-150 nm associated with the algae acquired from diseased corals (Cervino et al., 2004). These cells have since been described as resembling a Phycodna-like virus (Fauquet and Fargette, 2005). Symbiotic algae of corals with CYBD exhibit a distorted morphology with reduced mitotic indices and chloroplast function.

Although the above studies have correlated dominance or abundance of VLPs in different health states, disease causation cannot be confirmed without inoculation experiments or tests of the molecular Koch's postulates (Falkow, 2004, 1988), which have not so far been conducted. Profound shifts in the associated microbiome in diseased and environmentally- 
stressed hosts are commonly observed, but Lesser et al., (2007) have questioned whether coral diseases are generally caused by a primary infection (exposure of a healthy host to a virulent pathogen, causing disease) or more frequently represent secondary infections by non-specific opportunistic pathogens following environmental perturbation and reduced immunity. As colonial animals with a relatively simple body plan, corals exhibit rather indistinct disease signs (e.g. tissue lesions), and therefore the same visual disease signs might be produced by different primary pathogens (Cervino et al., 2001; Rosenberg et al., 2007; Sweet et al., 2011). Additionally, molecular metagenetic studies typically show co-infection by a number of potential causal agents (Sweet and Bythell, 2015, 2012), such that a primary infectious agent may be difficult to distinguish and studies applying challenge experiments with pure cultures have not so far controlled for or monitored the effects on these other members of the disease consortium (a recent exception being Séré et al., 2015). This has led some to suggest that polymicrobial infection, which is widely accepted to be the case in black band disease (Miller and Richardson, 2011), may be more widespread and apply to other common coral diseases such as white syndrome (Sweet and Bythell, 2015). Given the diversity and abundance of eukaryote viruses in corals, and the observations of their association with a variety of diseases (above), it is clear that viruses may act as primary, secondary and/or coinfectious agents of coral diseases. Distinguishing between these different roles to understand the causes of the serious ongoing global outbreaks of coral diseases is a critical challenge for coral reef science.

\section{Viruses associated with the symbiotic algae}

Viruses have now been described in numerous studies associated with the corals' symbiotic algae. Wilson et al., (2001) were the first to propose a viral infection as a cause of cell damage during bleaching in symbiotic algae of the sea anemone Anemonia viridis. Icosahedral VLPS $\sim 40-50 \mathrm{~nm}$ in diameter were observed in response to heat stress experiments, and the authors proposed that latent viral infections may be involved in the cellular pathogenesis of bleaching. Since then, numerous other types of viruses have been described in corals symbiotic algae, including; filamentous (Lohr et al., 2007), Phycodnavirus-like (Davy and Patten, 2007), Paramyxoviridae-like (Fauquet and Fargette, 2005), Mimiviridae-like (Claverie et al., 2009), and more recently Circoviridae and Nanoviridae-like viruses (Correa et al., 2013). Another recent study has shown via histology and metagenomics the presence of herpes-like 
VLPs in corals associated with an in situ bleaching event, together with evidence of a megavirus associated with the symbiotic algae of the coral (Correa et al., 2016).

Filamentous viruses associated with symbiotic algae have been shown to range from $200 \mathrm{~nm}$ to $2 \mu \mathrm{m}$ in length and resemble viruses belonging to the families Closteroviridae (Lohr et al., 2007), Flexiviridae and Potyviridae (Fauquet and Fargette, 2005). During ex situ UV exposure experiments, the symbiotic algae have been observed to become fully lysed and their abundance decrease rapidly. However, there is still uncertainty regarding how much of this lysis and decrease in abundance is due to photochemical UV damage or viral lysis (Lawrence et al., 2015). However, in support of the role of the viruses in the lysis, members of all three of these RNA viral families are well described plant pathogens in terrestrial ecosystems (Fauquet and Fargette, 2005). Other rod-like filamentous viruses have also been noted in other studies resembling Tobamoviruses, Tobraviruses, Pecluviruses, Pomoviruses (all in the family Virgaviridae) and Benyviruses (Fauquet and Fargette, 2005). Again, members of these genera are also well described plant pathogens (Adams et al., 2009; Rush, 2003).

In in situ field studies, Correa et al. (2012) found two algae-infecting viruses associated with the coral Montastraea cavernosa. These included a dsDNA large DNA virus (NCLDV) associated with the nucleus and cytoplasm and a +ssRNA virus. Interestingly, the +ssRNA virus appears to be similar to the virus HcRNAV that infects another dinoflagellate, Heterocapsa circularisquama (Tomaru et al., 2004) and/or the virus HaRNAV that infects the mixotrophic alga Heterosigma akashiwo (Lang et al., 2004). Both these well-described dinoflagellate viruses (HcRNAV and HaRNAV) are well known for their ability to lyse their unicellular algal hosts. Such viral lysis is considered an important factor in $H$. circularisquama and $H$. akashiwo bloom terminations (Nagasaki et al., 2004).

In corals, the above algae-infecting viruses have been shown to increase in abundance in both the algae and the coral host cells of diseased tissues. These findings suggest that they could be causing cell lysis of the algae either directly and/or indirectly by compromising the coral cells and causing a breakdown in the coral-algal symbiosis (Lawrence et al., 2014). To date, lysis by these viruses has not been directly linked to bleaching events in the field, but their ability to lyse the algal cells following thermal (Davy et al., 2006; Wilson et al., 2001) and/or UV stress (Lawrence et al., 2015; Lohr et al., 2007) indicates that this possible mechanism of 
symbiotic algal cell death needs further investigation. Indeed the algal-viral interactions observed in corals resemble those seen in other algal-virus interactions, such as Emiliania huxleyi virus 86 (Mackinder et al., 2009) and Phaeocystis pouchetti virus 1 (Jacobsen et al., 1996). However, the coral-specific viruses appear to lack initial penetration and eclipse periods in the majority of cases, although it has been argued that a latent viral infection could explain the apparent lack of these steps (adsorption, penetration and uncoating).

\section{Methods used to identify viruses in corals}

Numerous approaches have been used to describe viruses in various organisms including: electron microscopy (Davy and Patten, 2007; Wilson et al., 2001), PCR-based representational difference analysis (Chang et al., 1994), DNA in situ hybridization (Teifke et al., 2000), immuno-histochemistry (Gouda et al., 2010), flow cytometry (Sivaraman et al., 2013), and PCR and next generation sequencing (NGS) (Marston et al., 2013).

NGS is argued to be the only way to comprehensively assess the whole virome, since viruses lack a common phylogenetic marker. However, this raises considerable bioinformatics challenges with regard to the detection of viral sequence in mixed environmental samples and a recent study has shown that viral metagenomes exhibit significant contamination with cellular sequences (Roux et al., 2013). A further complication with this approach is the low representation of viruses in the sequence databases. For example, low levels of archaeal viruses found in the majority of studies conducted so far may be a result of the lack of representative sequences in these public databases (Marhaver et al., 2008; Thurber and Correa, 2011; Vega Thurber et al., 2008). This is perhaps the major current constraint associated with viral studies, however database coverage is improving rapidly and the availability of tools for virome analysis of metagenomics data (e.g. METAVIR http://metavirmeb.univ-bpclermont.fr/) is facilitating rapid development in this research area. The efficiency of virome metagenomics analyses can be improved via methods of enrichment. Enriching for total viral material within a sample can be achieved by physical methods early in the sample preparation process, including reducing the amount of contaminating non-viral nucleic acid, which in turn can be obtained via combinations of centrifugation, filtration and nuclease treatments (reviewed by Hall et al., 2014). Further enrichment is also possible after this step, either via sequence-independent enrichment using random hexamers and/or 
targeted enrichment of specific viruses. However, it has been argued that all of these approaches may be needed in combination in order to assemble whole genomes of certain viruses from uncultured primary samples (Depledge et al., 2011).

In addition to enrichment techniques, a variety of methods are necessary to detect both DNA and RNA viruses. For example, one specific technique that has recently been successfully applied is Random Priming (RP)-mediated Sequence Independent Single-Primer Amplification (RP-SISPA). The RP-SISPA method is based on random reverse transcription of viral RNA followed by annealing of excess primers to cDNA and conversion into dsDNA by Klenow polymerase and PCR amplification (for more detail see Djikeng and Spiro, 2009). However, similar to other NGS approaches, RP-SISPA has limitations. Primarily, there is an apparent template-dependent amplification bias, which results in uneven sequencing depth within and among genomes (Rosseel et al., 2013). RP-SISPA also has a bias for amplifying the dominant sequences associated with metagenomic samples (Weynberg et al. 2014), which has resulted in the majority of sequences retrieved using this approach belonging to dsDNA viruses, which have larger genomes relative to other viral types (Weynberg et al. 2014).

One shared limitation between different NGS metagenomics approaches is the inability to confirm associations of certain viruses with specific compartments of the organism. In order to do this, the most common approach is transmission electron microscopy (TEM). This technique was first reported in the detection of VLPS within a cnidarian by Wilson and Chapman, (2001) and has since been utilised to describe the presence (or absence) of numerous VLPs in many more studies over recent years. However, whilst the observation of VLPs in TEM images may well indicate evidence for viral infection, caution is needed when attempting to interpret pathogenesis due to processing artefacts and particles of non-viral origin in tissue thin-sections often associated with infection.

Isolation of viruses is also important to allow full characterisation and for use in infection studies. Commonly used methods for virus isolation and purification share similar limitations to the culture-independent techniques described above, namely they appear to exclude certain viruses (for review see Thurber and Correa, 2011) and as of yet there has been no successful isolation of any of the above viruses described associated with the coral holobiont. 
Of the 50 or so families of viruses that have been detected in more than one metagenomic study (reviewed by Wood-Charlson et al. 2015), about 22\% belong to bacterial or archaealspecific families of lytic phage viruses. Additionally, members of the non-lytic filamentous and rod-shaped Inoviridae have commonly been detected, that are important in horizontal gene transfer within microbial communities. Three families that infect unicellular algae have been detected, including the Phycodnaviridae, Marnaviridae and Alvernaviridae. Phycodnaviridae (PDV) are perhaps the best-characterized group of algal viruses (Clerissi et al., 2014; Wilson et al., 2009) and form their own monophyletic group that contains six described genera, all of which are large, icosahedral in shape and contain large DNA genomes (ranging from 160 to upwards of 560 bp). PDVs have been described associated with numerous different organisms, including; the toxic raphidophyte alga Heterosigma akashiwo (Wilson et al., 2009) and the coccolithphorid Emiliania huxleyi (Schroeder et al., 2002). In addition to families infecting unicellular algae, a number of coral-associated families are known to infect plants and/or fungi and protists, including the Geminivirdae, Nanoviridae, Tymoviridae, Potyviridae, Tombusviridae, Caulimoviridae, Alphaflexiviridae, Endornaviridae, Partitiviridae and Reoviridae (Wood-Charlson et al. 2015). While some of these are undoubtedly contaminants from plankton communities, or possible terrestrial contaminants from land run-off, several of these have been detected specifically in the coral algal symbionts, reviewed above, and may be important to their health and disease. Nanoviridae and Geminiviridae for example have been routinely identified in almost every study of coral viruses. Interestingly viruses from these families are often associated with sewage, which may highlight links between the presence of certain types of viruses and environment degradation (Soffer et al., 2014). Indeed studies have shown that viral abundance in corals is proportional to the concentration of local inorganic nutrients and human population centres (Dinsdale et al., 2008; Thurber and Correa, 2011).

Certain 'human specific' viruses have also been shown to be present within corals, perhaps due to anthropogenic pollution (Futch et al., 2010). Surprisingly, in fact, a large proportion (>20\%) of sequences identified in coral-associated metagenomes belong to families that have only previously been isolated from vertebrates, including members of the Herpesviridae, Adenoviridae, Asfarviridae, Papillomaviridae, Coronaviridae, Picornaviridae, Astroviridae, Caliciviridae, Arenaviridae and Retroviridae. Some of these are likely to be environmental 
contaminants with no roles in coral ecology, but several are routinely detected in coral metagenomics studies, suggesting that the full diversity of these families has not yet been described and they include coral-associated taxa. Herpesviruses for example, are some of the most commonly observed viruses associated with coral studies to date (Correa et al., 2016; Houldcroft and Breuer, 2015; Marhaver et al., 2008; Soffer et al., 2014; Thurber and Correa, 2011; Vega Thurber et al., 2008). Herpesviruses are dsDNA viruses that have been shown to cause diseases in both terrestrial and aquatic organisms (Houldcroft and Breuer, 2015) and typically infect large proportions of their target population, spreading through a variety of horizontal and vertical routes.

Finally, $20 \%$ of the families detected in coral metagenomes to date (Wood-Charlson et al. 2015) are known to infect a wide variety of invertebrate hosts or include invertebrate-specific viruses. These include the Malacoherpesviridae, Ascoviridae, Baculoviridae, Hytrosaviridae, Nimaviridae, Nudiviridae, Polydnaviridae, Dicistroviridae, Iridoviridae, Poxviridae, Parvoviridae and Flaviviridae. These families are therefore the most likely candidates where potential coral pathogens may be found (Thurber and Correa, 2011; van Oppen et al., 2009). The Malacoherpesviridae, for example, includes the Oyster herpesvirus (OsHV-1) and is a likely candidate coral pathogen. For a summary table of the current families identified in coral hosts we refer readers to the meta-analysis of Wood-Charlson et al. (2015).

Future direction of coral disease studies

The advent of next generation sequencing and metagenomics approaches makes a characterization of the entire microbiome of corals a feasible proposition. There are still technical challenges to bias-free characterisation of the virome, but rapid progress is being made. It is likely that viruses act both as causal agents of disease and as modifiers of bacterial and other microbial diseases of corals. All these processes will be influenced directly by environmental conditions and indirectly by effects on host immune defences. However, coral reef science lags far behind the health sciences with regard to the concept and assessment of disease causation, where some have even questioned whether disease causation is a valid question (Lipton and Ødegaard, 2005).

Russo and Williamson (2007) revisited the nine criteria of disease causation expounded by Bradford-Hill in 1986. These nine criteria, combining probabilistic and mechanistic 
considerations are intended to be applied in sum, with a stronger argument for a causal relationship being made when evidence is provided for more of these criteria. These arguments indicate that in coral disease research, we should continue to undertake research to strengthen (or otherwise) the assessment of causation in disease and use caution in referring to 'known' and 'unknown' coral diseases, when there are none that have been comprehensively studied across all of the Bradford-Hill criteria. One significant advantage that coral disease research has over medical sciences is the ability to undertake controlled exposure experiments to determine mortality in response to isolated agents, thereby testing Koch's postulates. However we argue that to adequately test Koch's postulates in corals we must combine these traditional C19th approaches with C21st technological advancements. Below we have outlined 7 steps which will aid coral researchers in assessing causation. We propose that to demonstrate causation studies should;

1) Show consistent up-regulation of the proposed causal agent (or sequences related to it) in all cases of the disease in question (spanning different locations and where possible, different host species).

2) Characterise the disease in question using multivariate methods, including field observations (e.g. via tagged and monitored colonies, assessing lesion progression); on a cellular level (e.g. immuno-histopathology) and comprehensive assessment of the microbiome in healthy, apparently healthy and diseased colonies (e.g. metagenomics). A stronger case can be made where the disease pathogenesis can be both temporally and spatially (microscopically) correlated with activity of the suspected pathogen

3) Isolate the suspected agent/agents in culture and expose multiple, independent healthy host samples to these isolates with adequate controls (i.e. non-suspected members of the microbiome). Since the lack of adequate cell culture models precludes the culture of coral-associated viruses, this step may be limited at present to applications of filterable fractions (e.g. $<0.22 \mu \mathrm{m}$ ) to distinguish bacterial from viral infection.

4) Use whole-microbiome analyses to demonstrate that exposure (3) does not upregulate any other members of the microbiome in advance of the characteristic disease signs (2). 
5) Where (4) cannot be met, isolate and test any upregulated members of the microbiome as control inocula.

6) Assess the probabilistic risk of producing the disease signs (2) upon exposure ( 3 or 5), under a range of environmental conditions.

7) Demonstrate that the up-regulation of the suspected agent (or agents) in experimental trials is of a similar magnitude to those observed in field samples of the disease.

Thus a significant future development for coral viral disease research will be to establish in vitro culture methods to enable such experimental exposures (3.) However, the significant challenges faced in assessing disease causation should not be underestimated. Assessing causation must be viewed as a developing paradigm, supported by multiple lines of evidence rather than a simple test, and requires significant collaborative research effort.

\section{Conclusions.}

Characterization of changes in VLP diversity and abundance in health and disease do not in themselves elucidate their various possible ecological roles as pathogens and agents controlling other potential pathogen populations associated with corals. While both metagenomics and TEM-based histological studies show that viruses are highly likely to be involved in coral diseases, these approaches now need to be combined to show specific roles of viruses in pathogenesis and their interactions with other members of the microbiome. Currently, about $\sim 22$ coral diseases have been described, however a large proportion of them have no known etiological agent (Sheridan et al., 2013; Sweet et al., 2011) or have had multiple potential agents described depending on the host infected and location (Bourne et al., 2015). Therefore searching for potential viral pathogens should clearly be a priority, but integrated studies are needed to assess causation and elucidate the no doubt highly complex roles of viruses in health, environmental stress responses and disease. Rapid developments in DNA sequencing technologies, virome sample preparation and availability of bioinformatics tools, as well as the availability of reference sequences in the online databases, make wholemicrobiome analyses feasible for the first time, but the critical next step will be to integrate such studies with in vitro culture and challenge experiments in carefully controlled conditions to assess the roles of viruses in health and disease. We would still note that even such a 
comprehensive test would fall short of meeting the Bradford-Hill criteria, and that such research would support, rather than prove a hypothesis of causation (Russo and Williamson, 2007). As such, we propose the 7 steps above as a mechanistic test of disease causation, noting that further epidemiological studies (e.g. Russo and Williamson 2007) would be necessary to elucidate the complex holobiont-pathogen-environment interactions in disease causation.

\section{References}

Abedon, S.T., 2011. Lysis from without. Bacteriophage 1, 46-49. doi:10.4161/bact.1.1.13980

Adams, M.J., Antoniw, J.F., Kreuze, J., 2009. Virgaviridae: a new family of rod-shaped plant viruses. Arch. Virol. 154, 1967-72. doi:10.1007/s00705-009-0506-6

Atad, I., Zvuloni, A., Loya, Y., Rosenberg, E., 2012. Phage therapy of the white plague-like disease of Favia favus in the Red Sea. Coral Reefs 31, 665-670. doi:10.1007/s00338012-0900-5

Barash, Y., Sulam, R., Loya, Y., Rosenberg, E., 2005. Bacterial Strain BA-3 and a filterable factor cause a white plague-like disease in corals from the Eilat coral reef. Aquat. Microb. Ecol. 40, 183-189. doi:10.3354/ame040183

Barr, J.J., Auro, R., Furlan, M., Whiteson, K.L., Erb, M.L., Pogliano, J., Stotland, A., Wolkowicz, R., Cutting, A.S., Doran, K.S., Salamon, P., Youle, M., Rohwer, F., 2013. Bacteriophage adhering to mucus provide a non-host-derived immunity. Proc. Natl. Acad. Sci. 110, 10771-10776. doi:10.1073/pnas.1305923110

Baumann, J., Kouassi, N.M., Foni, E., Klenk, H.-D., Matrosovich, M., 2016. H1N1 Swine Influenza Viruses Differ from Avian Precursors by a Higher pH Optimum of Membrane Fusion. J. Virol. 90, 1569-1577. doi:10.1128/JVI.02332-15

Bergh, O., Børsheim, K.Y., Bratbak, G., Heldal, M., 1989. High abundance of viruses found in aquatic environments. Nature 340, 467-8. doi:10.1038/340467a0

Bettarel, Y., Bouvier, T., Nguyen, H.K., Thu, P.T., 2015. The versatile nature of coral- 
Bourne, D.G., Ainsworth, T.D., Pollock, F.J., Willis, B.L., 2015. Towards a better understanding of white syndromes and their causes on Indo-Pacific coral reefs. Coral Reefs 34, 233-242. doi:10.1007/s00338-014-1239-x

Bruno, J.F., Selig, E.R., Casey, K.S., Page, C. a., Willis, B.L., Harvell, C.D., Sweatman, H., Melendy, A.M., 2007. Thermal stress and coral cover as drivers of coral disease outbreaks. PLoS Biol. 5, 1220-1227. doi:10.1371/journal.pbio.0050124

Cervino, J., Goreau, T.J., Nagelkerken, I., Smith, G.W., Hayes, R., 2001. Yellow band and dark spot syndromes in Caribbean corals: Distribution, rate of spread, cytology, and effects on abundance and division rate of zooxanthellae. Hydrobiologia 460, 53-63. doi:10.1023/A:1013166617140

Cervino, J.M., Hayes, R., Goreau, T.J., Smith, G.W., 2004. Zooxanthellae regulation in yellow blotch/band and other coral diseases contrasted with temperature related bleaching: In situ destruction vs expulsion. Symbiosis 37, 63-85. doi:10.1128/AEM.70.11.6855

Cervino, J.M., Thompson, F.L., Gomez-Gil, B., Lorence, E.A., Goreau, T.J., Hayes, R.L., Winiarski-Cervino, K.B., Smith, G.W., Hughen, K., Bartels, E., 2008. The Vibrio core group induces yellow band disease in Caribbean and Indo-Pacific reef-building corals. J. Appl. Microbiol. 105, 1658-1671. doi:10.1111/j.1365-2672.2008.03871.x

Chang, Y., Cesarman, E., Pessin, M.S., Lee, F., Culpepper, J., Knowles, D.M., Moore, P.S., 1994. Identification of herpesvirus-like DNA sequences in AIDS-associated Kaposi's sarcoma. Science 266, 1865-9.

Claverie, J.-M., Grzela, R., Lartigue, A., Bernadac, A., Nitsche, S., Vacelet, J., Ogata, H., Abergel, C., 2009. Mimivirus and Mimiviridae: giant viruses with an increasing number of potential hosts, including corals and sponges. J. Invertebr. Pathol. 101, 172-80. doi:10.1016/j.jip.2009.03.011

Clerissi, C., Grimsley, N., Ogata, H., Hingamp, P., Poulain, J., Desdevises, Y., 2014. Unveiling of the Diversity of Prasinoviruses (Phycodnaviridae) in Marine Samples by Using HighThroughput Sequencing Analyses of PCR-Amplified DNA Polymerase and Major Capsid 
563

564

565

566

567

568

569

570

571

572

573

574

575

576

577

578

579

580

581

582

583

584

585

586

587

588

589

Cohen, Y., Joseph Pollock, F., Rosenberg, E., Bourne, D.G., 2013. Phage therapy treatment of the coral pathogen Vibrio coralliilyticus. Microbiologyopen 2, 64-74. doi:10.1002/mbo3.52

Correa, A., Ainsworth, T., Rosales, S., Thurber, A., Butler, C., Vega Thurber, R., 2016. Viral outbreak in corals associated with an in situ bleaching event: Atypical herpes-like viruses and a new megavirus infecting symbiodinium. Front. Microbiol. 7, 127. doi:10.3389/fmicb.2016.00127

Correa, A.M.S., Ainsworth, T.D., Rosales, S.M., Thurber, A.R., Butler, C.R., Vega Thurber, R.L., 2016. Viral Outbreak in Corals Associated with an In Situ Bleaching Event: Atypical Herpes-Like Viruses and a New Megavirus Infecting Symbiodinium. Front. Microbiol. 7, 127. doi:10.3389/fmicb.2016.00127

Correa, A.M.S., Welsh, R.M., Vega Thurber, R.L., 2013. Unique nucleocytoplasmic dsDNA and +ssRNA viruses are associated with the dinoflagellate endosymbionts of corals. ISME J. 7, 13-27. doi:10.1038/ismej.2012.75

Cróquer, A., Bastidas, C., Elliott, A., Sweet, M., 2013. Bacterial assemblages shifts from healthy to yellow band disease states in the dominant reef coral Montastraea faveolata. Environ. Microbiol. Rep. 5, 90-6. doi:10.1111/j.1758-2229.2012.00397.x

Daniels, C.A., Baumgarten, S., Yum, L.K., Michell, C.T., Bayer, T., Arif, C., Roder, C., Weil, E., Voolstra, C.R., 2015. Metatranscriptome analysis of the reef-building coral Orbicella faveolata indicates holobiont response to coral disease. Front. Mar. Sci. 2, 62. doi:10.3389/fmars.2015.00062

Danovaro, R., Corinaldesi, C., Dell'Anno, A., Fuhrman, J.A., Middelburg, J.J., Noble, R.T., Suttle, C.A., 2011. Marine viruses and global climate change. FEMS Microbiol. Rev. 35, 993-1034. doi:10.1111/j.1574-6976.2010.00258.x

Davy, J., Patten, N., 2007. Morphological diversity of virus-like particles within the surface microlayer of scleractinian corals. Aquat. Microb. Ecol. 47, 37-44. doi:10.3354/ame047037 
Davy, S.K., Burchett, S.G., Dale, A.L., Davies, P., Davy, J.E., Muncke, C., Hoegh-Guldberg, O., Wilson, W.H., 2006. Viruses: agents of coral disease? Dis. Aquat. Organ. 69, 101-10. doi:10.3354/dao069101

Depledge, D.P., Palser, A.L., Watson, S.J., Lai, I.Y.-C., Gray, E.R., Grant, P., Kanda, R.K., Leproust, E., Kellam, P., Breuer, J., 2011. Specific Capture and Whole-Genome Sequencing of Viruses from Clinical Samples. PLoS One 6, e27805. doi:10.1371/journal.pone.0027805

Dinsdale, E.A., Pantos, O., Smriga, S., Edwards, R.A., Angly, F., Wegley, L., Hatay, M., Hall, D., Brown, E., Haynes, M., Krause, L., Sala, E., Sandin, S.A., Thurber, R.V., Willis, B.L., Azam, F., Knowlton, N., Rohwer, F., 2008. Microbial Ecology of Four Coral Atolls in the Northern Line Islands. PLoS One 3, e1584. doi:10.1371/journal.pone.0001584

Djikeng, A., Spiro, D., 2009. Advancing full length genome sequencing for human RNA viral pathogens. Future Virol. 4, 47-53. doi:10.2217/17460794.4.1.47

Douglas, a. E., 2003. Coral bleaching - How and why? Mar. Pollut. Bull. 46, 385-392. doi:10.1016/S0025-326X(03)00037-7

Falkow, S., 2004. Opinion: Molecular Koch's postulates applied to bacterial pathogenicity a personal recollection 15 years later. Nat. Rev. Microbiol. 2, 67-72. doi:10.1038/nrmicro799

Falkow, S., 1988. Molecular Koch's postulates applied to microbial pathogenicity. Rev. Infect. Dis. 10 Suppl 2, S274-6.

Fauquet, C., Fargette, D., 2005. International Committee on Taxonomy of Viruses and the 3,142 unassigned species. Virol. J. 2, 64. doi:10.1186/1743-422X-2-64

Fuhrman, J.A., 1999. Marine viruses and their biogeochemical and ecological effects. Nature 399, 541-8. doi:10.1038/21119

Futch, J.C., Griffin, D.W., Lipp, E.K., 2010. Human enteric viruses in groundwater indicate offshore transport of human sewage to coral reefs of the Upper Florida Keys. Environ. Microbiol. 12, 964-974. doi:10.1111/j.1462-2920.2010.02141.x 
Glasl, B., Herndl, G.J., Frade, P.R., 2016. The microbiome of coral surface mucus has a key role in mediating holobiont health and survival upon disturbance. ISME J. doi:10.1038/ismej.2016.9

Gouda, I., Nada, O., Ezzat, S., Eldaly, M., Loffredo, C., Taylor, C., Abdel-Hamid, M., 2010. Immunohistochemical detection of hepatitis C virus (genotype 4) in B-cell NHL in an Egyptian population: correlation with serum HCV-RNA. Appl. Immunohistochem. Mol. Morphol. 18, 29-34. doi:10.1097/PAl.0b013e3181ae9e82

Gustavsen, J.A., Winget, D.M., Tian, X., Suttle, C.A., 2014. High temporal and spatial diversity in marine RNA viruses implies that they have an important role in mortality and structuring plankton communities. Front. Microbiol. 5, 703. doi:10.3389/fmicb.2014.00703

Hall, R.J., Wang, J., Todd, A.K., Bissielo, A.B., Yen, S., Strydom, H., Moore, N.E., Ren, X., Huang, Q.S., Carter, P.E., Peacey, M., 2014. Evaluation of rapid and simple techniques for the enrichment of viruses prior to metagenomic virus discovery. J. Virol. Methods 195, 194-204. doi:10.1016/j.jviromet.2013.08.035

Halstead, S.B., Cohen, S.N., 2015. Dengue Hemorrhagic Fever at 60 Years: Early Evolution of Concepts of Causation and Treatment. Microbiol. Mol. Biol. Rev. 79, 281-291. doi:10.1128/MMBR.00009-15

Houldcroft, C.J., Breuer, J., 2015. Tales from the crypt and coral reef: the successes and challenges of identifying new herpesviruses using metagenomics. Front. Microbiol. 6, 188. doi:10.3389/fmicb.2015.00188

Israely, T., Banin, E., Rosenberg, E., 2001. Growth, differentiation and death of Vibrio shiloi in coral tissue as a function of seawater temperature. Aquat. Microb. Ecol. 24, 1-8. doi:10.3354/ame024001

Jacobsen, A., Bratbak, G., Heldal, M., 1996. Isolation and Characterization of a Virus Infecting Phaeocystis Pouchetii (prymnesiophyceae)1. J. Phycol. 32, 923-927. doi:10.1111/j.0022-3646.1996.00923.x

Jacquet, S., Bratbak, G., 2003. Effects of ultraviolet radiation on marine virus-phytoplankton 
Kemp, D.W., Rivers, A.R., Kemp, K.M., Lipp, E.K., Porter, J.W., Wares, J.P., 2015. Spatial Homogeneity of Bacterial Communities Associated with the Surface Mucus Layer of the Reef-Building Coral Acropora palmata. PLoS One 10, e0143790. doi:10.1371/journal.pone.0143790

King, A.M.Q., Adams, M.J., Carstens, E.B., Lefkowitz, E.J., 2012. Virus Taxonomy Classification and Nomenclature of Viruses Ninth Report of the International Committee on Taxonomy of Viruses. Int. Union Microbiol. Soc. Virol. Div.

Labonté, J.M., Suttle, C.A., 2013. Previously unknown and highly divergent ssDNA viruses populate the oceans. ISME J. 7, 2169-2177. doi:10.1038/ismej.2013.110

Lang, A.S., Culley, A.I., Suttle, C.A., 2004. Genome sequence and characterization of a virus (HaRNAV) related to picorna-like viruses that infects the marine toxic bloom-forming alga Heterosigma akashiwo. Virology 320, 206-17. doi:10.1016/j.virol.2003.10.015

Lawrence, S.A., Davy, J.E., Aeby, G.S., Wilson, W.H., Davy, S.K., 2014. Quantification of viruslike particles suggests viral infection in corals affected by Porites tissue loss. Coral Reefs 33, 687-691. doi:10.1007/s00338-014-1168-8

Lawrence, S.A., Davy, J.E., Wilson, W.H., Hoegh-Guldberg, O., Davy, S.K., 2015. Porites white patch syndrome: associated viruses and disease physiology. Coral Reefs 34, 249-257. doi:10.1007/s00338-014-1218-2

Leruste, A., Bouvier, T., Bettarel, Y., 2012. Enumerating Viruses in Coral Mucus. Appl. Environ. Microbiol. 78, 6377-6379. doi:10.1128/AEM.01141-12

Lesser, M.P., Bythell, J.C., Gates, R.D., Johnstone, R.W., Hoegh-Guldberg, O., 2007. Are infectious diseases really killing corals? Alternative interpretations of the experimental and ecological data. J. Exp. Mar. Bio. Ecol. 346, 36-44. doi:10.1016/j.jembe.2007.02.015

Lesser, M.P., Farrell, J.H., 2004. Exposure to solar radiation increases damage to both host tissues and algal symbionts of corals during thermal stress. Coral Reefs 23, 367-377. 
Lipton, R., $\varnothing$ degaard, T., 2005. Causal thinking and causal language in epidemiology: it's in the details. Epidemiol. Perspect. Innov. 2, 8. doi:10.1186/1742-5573-2-8

Lohr, J., Munn, C.B., Wilson, W.H., 2007. Characterization of a Latent Virus-Like Infection of Symbiotic Zooxanthellae. Appl. Environ. Microbiol. 73, 2976-2981. doi:10.1128/AEM.02449-06

Mackinder, L.C.M., Worthy, C.A., Biggi, G., Hall, M., Ryan, K.P., Varsani, A., Harper, G.M., Wilson, W.H., Brownlee, C., Schroeder, D.C., 2009. A unicellular algal virus, Emiliania huxleyi virus 86, exploits an animal-like infection strategy. J. Gen. Virol. 90, 2306-2316. doi:10.1099/vir.0.011635-0

Maranger, R., del Giorgio, P., Bird, D., 2002. Accumulation of damaged bacteria and viruses in lake water exposed to solar radiation. Aquat. Microb. Ecol. 28, 213-227. doi:10.3354/ame028213

Marhaver, K.L., Edwards, R.A., Rohwer, F., 2008. Viral communities associated with healthy and bleaching corals. Environ. Microbiol. 10, 2277-86. doi:10.1111/j.14622920.2008.01652.x

Marston, D.A., McElhinney, L.M., Ellis, R.J., Horton, D.L., Wise, E.L., Leech, S.L., David, D., de Lamballerie, X., Fooks, A.R., 2013. Next generation sequencing of viral RNA genomes. BMC Genomics 14, 444. doi:10.1186/1471-2164-14-444

Miller, A.W., Richardson, L.L., 2011. A meta-analysis of 16S rRNA gene clone libraries from the polymicrobial black band disease of corals. FEMS Microbiol. Ecol. 75, 231-41. doi:10.1111/j.1574-6941.2010.00991.x

Nagasaki, K., Tomaru, Y., Nakanishi, K., Hata, N., Katanozaka, N., Yamaguchi, M., 2004. Dynamics of Heterocapsa circularisquama (Dinophyceae) and its viruses in Ago Bay, Japan. Aquat. Microb. Ecol. doi:10.3354/ame035219

Nguyen-Kim, H., Bouvier, T., Bouvier, C., Doan-Nhu, H., Nguyen-Ngoc, L., Rochelle-Newall, E., Baudoux, A.C., Desnues, C., Reynaud, S., Ferrier-Pages, C., Bettarel, Y., 2014. High 
occurrence of viruses in the mucus layer of scleractinian corals. Environ. Microbiol. Rep. 6, 675-682. doi:10.1111/1758-2229.12185

Noble, R.T., Fuhrman, J.A., 1997. Virus decay and its causes in coastal waters. Appl. Environ. Microbiol. 63, 77-83.

Patten, N.L., Harrison, P.L., Mitchell, J.G., 2008. Prevalence of virus-like particles within a staghorn scleractinian coral (Acropora muricata) from the Great Barrier Reef. Coral Reefs 27, 569-580. doi:10.1007/s00338-008-0356-9

Pollock, F., Wood-Charlson, E., van Oppen, M., Bourne, D., Willis, B., Weynberg, K., 2014. Abundance and morphology of virus-like particles associated with the coral Acropora hyacinthus differ between healthy and white syndrome-infected states. Mar. Ecol. Prog. Ser. 510, 39-43. doi:10.3354/meps10927

Ritchie, K.B., 2006. Regulation of microbial populations by coral surface mucus and mucusassociated bacteria. Mar. Ecol. Prog. Ser. 322, 1-14. doi:10.3354/meps322001

Roldão, A., Mellado, M.C.M., Castilho, L.R., Carrondo, M.J.T., Alves, P.M., 2010. Virus-like particles in vaccine development. Expert Rev. Vaccines 9, 1149-76. doi:10.1586/erv.10.115

Roossinck, M.J., 2015. Move over bacteria! Viruses make their mark as mutualistic microbial symbionts. J. Virol. JVI.02974-14. doi:10.1128/JVI.02974-14

Roossinck, M.J., 2011. The good viruses: viral mutualistic symbioses. Nat. Rev. Microbiol. 9, 99-108. doi:10.1038/nrmicro2491

Rosenberg, E., Koren, O., Reshef, L., Efrony, R., Zilber-Rosenberg, I., 2007. The role of microorganisms in coral health, disease and evolution. Nat. Rev. Microbiol. 5, 355-362. doi:10.1038/nrmicro1635

Rosseel, T., Van Borm, S., Vandenbussche, F., Hoffmann, B., van den Berg, T., Beer, M., Höper, D., 2013. The Origin of Biased Sequence Depth in Sequence-Independent Nucleic Acid Amplification and Optimization for Efficient Massive Parallel Sequencing. PLoS One 8, e76144. doi:10.1371/journal.pone.0076144 
Roux, S., Krupovic, M., Debroas, D., Forterre, P., Enault, F., 2013. Assessment of viral community functional potential from viral metagenomes may be hampered by contamination with cellular sequences. Open Biol. 3, 130160. doi:10.1098/rsob.130160

Rush, C.M., 2003. Ecology and epidemiology of benyviruses and plasmodiophorid vectors. Annu. Rev. Phytopathol. 41, 567-592. doi:10.1146/annurev.phyto.41.052002.095705

Russo, F., Williamson, J., 2007. Interpreting Causality in the Health Sciences. Int. Stud. Philos. Sci. 21, 157-170. doi:10.1080/02698590701498084

Sanders, R.W., Wickham, S.A., 1993. Planktonic protozoa and metazoa: predation, food quality and population control. Mar. Microb. Food Webs 7, 197-223.

Scanlan, D.J., Wilson, W.H., 1999. Application of molecular techniques to addressing the role of $\mathrm{P}$ as a key effector in marine ecosystems. Hydrobiologia 401, 149-175. doi:10.1023/A:1003742528262

Schroeder, D.C., Oke, J., Malin, G., Wilson, W.H., 2002. Coccolithovirus (Phycodnaviridae): Characterisation of a new large dsDNA algal virus that infects Emiliana huxleyi. Arch. Virol. 147, 1685-1698. doi:10.1007/s00705-002-0841-3

Séré, M.G., Tortosa, P., Chabanet, P., Quod, J.-P., Sweet, M.J., Schleyer, M.H., 2015. Identification of a bacterial pathogen associated with Porites white patch syndrome in the Western Indian Ocean. Mol. Ecol. 24, 4570-81. doi:10.1111/mec.13326

Seymour, J., Patten, N., Bourne, D., Mitchell, J., 2005. Spatial dynamics of virus-like particles and heterotrophic bacteria within a shallow coral reef system. Mar. Ecol. Prog. Ser. 288, 1-8. doi:10.3354/meps288001

Sheridan, C., Kramarsky-Winter, E., Sweet, M., Kushmaro, A., Leal, M.C., 2013. Diseases in coral aquaculture: Causes, implications and preventions. Aquaculture 396-399, 124135. doi:10.1016/j.aquaculture.2013.02.037

Sivaraman, D., Yeh, H.-Y., Mulchandani, A., Yates, M. V., Chen, W., 2013. Use of Flow Cytometry for Rapid, Quantitative Detection of Poliovirus-Infected Cells via TAT Peptide-Delivered Molecular Beacons. Appl. Environ. Microbiol. 79, 696-700. 
754

755

756

757

758

759

760

761

762

763

764

765

766

767

768

769

770

771

772

773

774

775

776

777

778

Soffer, N., Brandt, M.E., Correa, A.M.S., Smith, T.B., Thurber, R.V., 2014. Potential role of viruses in white plague coral disease. ISME J. 8, 271-83. doi:10.1038/ismej.2013.137

Soffer, N., Zaneveld, J., Vega Thurber, R., 2015. Phage-bacteria network analysis and its implication for the understanding of coral disease. Environ. Microbiol. 17, 1203-1218. doi:10.1111/1462-2920.12553

Suttle, C.A., 2007. Marine viruses - major players in the global ecosystem. Nat. Rev. Microbiol. 5, 801-812. doi:10.1038/nrmicro1750

Sweet, M., Bythell, J., 2015. White syndrome in Acropora muricata: nonspecific bacterial infection and ciliate histophagy. Mol. Ecol. 24, 1150-9. doi:10.1111/mec.13097

Sweet, M., Bythell, J., 2012. Ciliate and bacterial communities associated with White Syndrome and Brown Band Disease in reef-building corals. Environ. Microbiol. 14, 2184-99. doi:10.1111/j.1462-2920.2012.02746.x

Sweet, M., Jones, R., Bythell, J., 2011. Coral diseases in aquaria and in nature. J. Mar. Biol. Assoc. United Kingdom 92, 791-801. doi:10.1017/S0025315411001688

Sweet, M., Jones, R., Bythell, J., 2011. Coral diseases in aquaria and in nature. J. Mar. Biol. Assoc. United Kingdom 1-10.

Teifke, J.P., Löhr, C. V, Marschang, R.E., Osterrieder, N., Posthaus, H., 2000. Detection of chelonid herpesvirus DNA by nonradioactive in situ hybridization in tissues from tortoises suffering from stomatitis-rhinitis complex in Europe and North America. Vet. Pathol. 37, 377-85.

Teodoro, J.G., Branton, P.E., 1997. Regulation of apoptosis by viral gene products. J. Virol. 71, 1739-46.

Thurber, R.L.V., Correa, A.M.S., 2011. Viruses of reef-building scleractinian corals. J. Exp. Mar. Bio. Ecol. 408, 102-113. doi:10.1016/j.jembe.2011.07.030

Tomaru, Y., Katanozaka, N., Nishida, K., Shirai, Y., Tarutani, K., Yamaguchi, M., Nagasaki, K., 2004. Isolation and characterization of two distinct types of HcRNAV, a single-stranded 
RNA virus infecting the bivalve-killing microalga Heterocapsa circularisquama. Aquat. Microb. Ecol. 34, 207-218. doi:10.3354/ame034207

van Oppen, M.J.H., Leong, J.-A., Gates, R.D., 2009. Coral-virus interactions: A double-edged sword? Symbiosis 47, 1-8. doi:10.1007/BF03179964

Vega Thurber, R.L., Barott, K.L., Hall, D., Liu, H., Rodriguez-Mueller, B., Desnues, C., Edwards, R.A., Haynes, M., Angly, F.E., Wegley, L., Rohwer, F.L., 2008. Metagenomic analysis indicates that stressors induce production of herpes-like viruses in the coral Porites compressa. Proc. Natl. Acad. Sci. 105, 18413-18418. doi:10.1073/pnas.0808985105

Weynberg, K.D.. E.M.W.-C.C.A.S.M.J.H. van O., 2014. Generating viral metagenomes from the coral holobiont. Front. Microbiol. 5. doi:10.3389/fmicb.2014.00206

Wilson, W., Francis, I., Ryan, K., Davy, S., 2001. Temperature induction of viruses in symbiotic dinoflagellates. Aquat. Microb. Ecol. 25, 99-102. doi:10.3354/ame025099

Wilson, W.H., Chapman, D.M., 2001. Observation of virus-like particles in thin sections of the plumose anemone, Metridium senile. J. Mar. Biol. Assoc. UK 81, 879. doi:10.1017/S0025315401004726

Wilson, W.H., Dale, A.L., Davy, J.E., Davy, S.K., 2005. An enemy within? Observations of virus-like particles in reef corals. Coral Reefs 24, 145-148. doi:10.1007/s00338-0040448-0

Wilson, W.H., Van Etten, J.L., Allen, M.J., 2009. The Phycodnaviridae: the story of how tiny giants rule the world. Curr. Top. Microbiol. Immunol. 328, 1-42.

Wood-Charlson, E.M., Weynberg, K.D., Suttle, C.A., Roux, S., van Oppen, M.J.H., 2015. Metagenomic characterization of viral communities in corals: mining biological signal from methodological noise. Environ. Microbiol. 17, 3440-3449. doi:10.1111/14622920.12803 


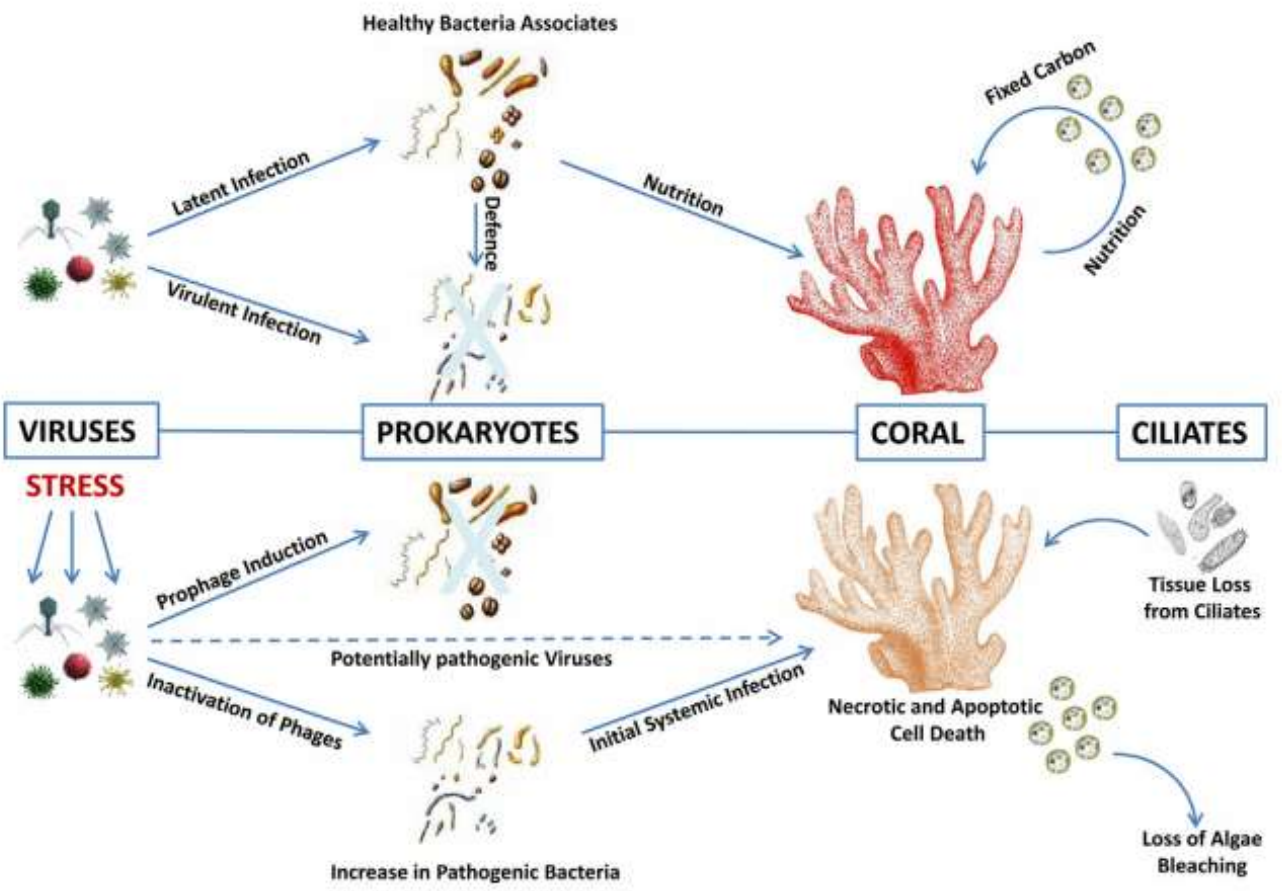

808 Figure 1. Schematic highlighting the various roles of the coral microbial associates and potential 809 pathogens in health and disease. 